\title{
New advances in leukaemia immunotherapy by the use of Chimeric Artificial Antigen Receptors (CARs): state of the art and perspectives for the near future
}

Ettore Biagi*, Virna Marin, Greta Maria Paola Giordano Attianese, Irene Pizzitola, Sarah Tettamanti, Elisabetta Cribioli and Andrea Biondi

\begin{abstract}
Leukaemia immunotherapy represents a fascinating and promising field of translational research, particularly as an integrative approach of bone marrow transplantation. Adoptive immunotherapy by the use of donor-derived expanded leukaemia-specific T cells has showed some kind of clinical response, but the major advance is nowadays represented by gene manipulation of donor immune cells, so that they acquire strict specificity towards the tumour target and potent lytic activity, followed by significant proliferation, increased survival and possibly antitumour memory state. This is achieved by gene insertion of Chimeric T-cell Antigen Receptors (CARs), which are artificial molecules containing antibody-derived fragments (to bind the specific target), joined with potent signalling T-Cell Receptor (TCR)-derived domains that activate the manipulated cells. This review will discuss the main application of this approach particularly focusing on the paediatric setting, raising advantages and disadvantages and discussing relevant perspectives of use in the nearest future.
\end{abstract}

Keywords: Leukaemia immunotherapy, cell therapy, gene therapy, chimeric artificial receptors

\section{Introduction}

Chimeric T-cell Antigen Receptors (CARs) are a fascinating bio-technologic step in the field of immunotherapy to orient the activity of immune cells towards specific molecular targets expressed on the cell surface of various tumours, including haematological malignancies. CARs are artificial T-cell receptors constituted by an antigen-recognizing extracellular domain derived from an antibody molecule linked to a T-cell triggering domain [1-4]. CARs are generated by joining the heavy and light chain variable regions of a monoclonal antibody, expressed as a single-chain Fragment variable (scFv) molecule, to an intracellular signalling domain, usually the zeta-chain of the TCR/CD3 complex or the gamma-chain from the Fc-epsilon-RI receptor Figure 1. $\mathrm{T}$ lymphocytes genetically engineered to express CARs

\footnotetext{
* Correspondence: e.biagi@hsgerardo.org
Centro di Ricerca Fondazione "Matilde Tettamanti", Clinica Pediatrica Azienda

* Correspondence: e.biagi@hsgerardo.org
Centro di Ricerca Fondazione "Matilde Tettamanti", Clinica Pediatrica Azienda Ospedaliera San Gerardo, Università Milano-Bicocca, via Pergolesi 33, Monza, 20900, Italy
}

(c) 2011 Biagi et al; licensee BioMed Central Ltd. This is an Open Access article distributed under the terms of the Creative Commons Attribution License (http://creativecommons.org/licenses/by/2.0), which permits unrestricted use, distribution, and reproduction in any medium, provided the original work is properly cited. secretion upon exposure to the respective target antigen. The CAR-mediated effector function may produce sustained tumour cell lysis more likely than humoral immune responses alone, based on the use of monoclonal antibodies. The perforin/granzyme killing mechanism may be effective against cells that are relatively resistant to antibody and complement, while cytokine secretion recruits additional components of the immune system, amplifying and prolonging the anti-tumour immune response. Moreover, effector $\mathrm{T}$ cells display efficient tumour penetration and homing capabilities [1-4].

The CAR approach permits to overcome the major limitations associated with the use of a "classical" TCR transgenic molecule. In fact, target recognition by CAR is non-MHC restricted and independent of antigen processing, therefore allowing its use in patients with different haplotypes and bypassing tumour escape due to $\mathrm{MHC}$-molecules down-regulation. In addition, CARs 


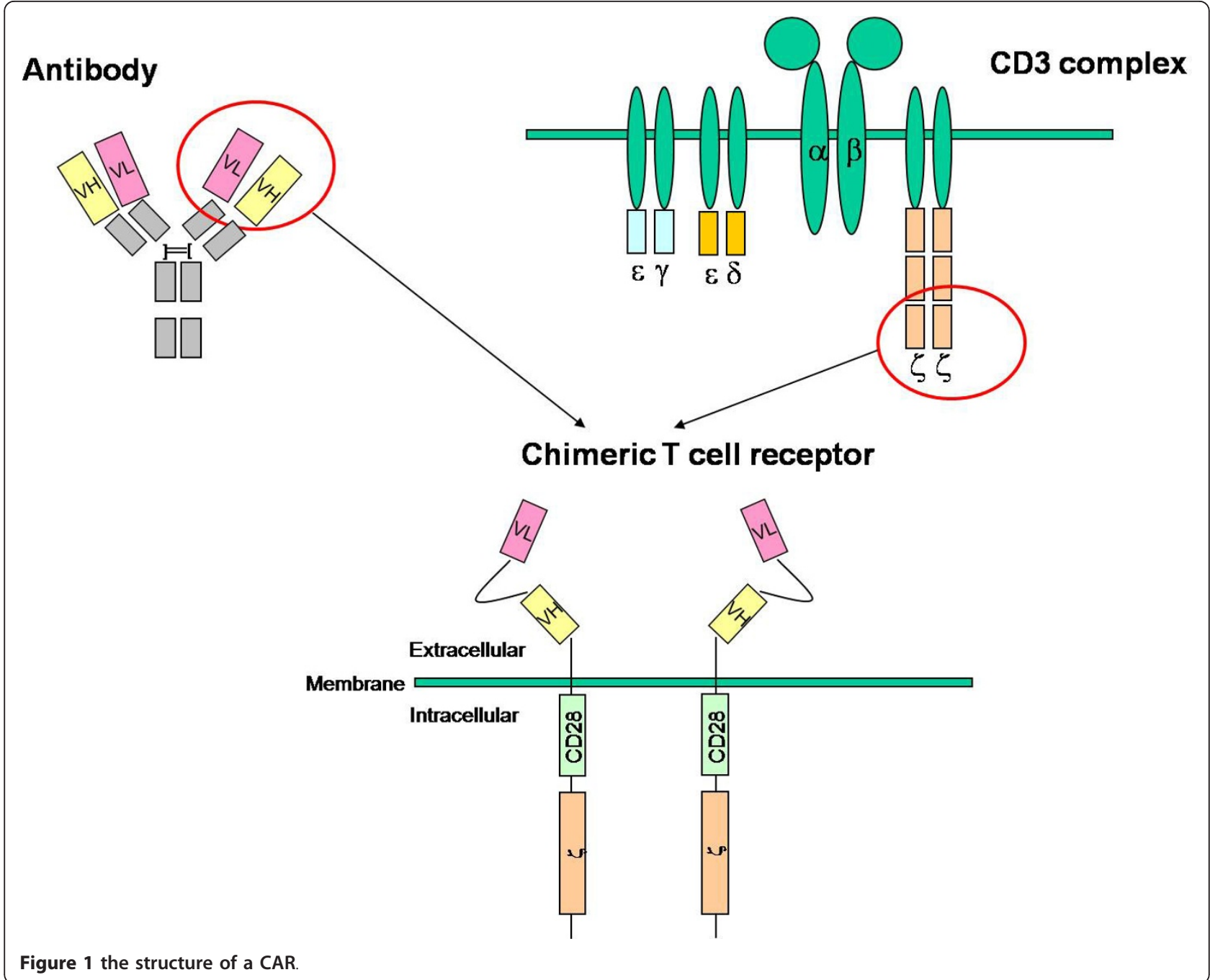

can be targeted toward molecules other than peptides, like carbohydrates and glycolipids, and there is no risk to trigger unpredictable and potentially harmful specificities, as it may happen with transduced TCR, that could form hybrids with the endogenous TCR [1-4].

Different CARs have been generated so far $[2,3,5]$, against a wide range of surface molecules expressed by many solid tumours and haematological malignancies. The efficacy of this strategy has been recently proved by a phase I clinical trial in patients with neuroblastoma. In this study, the authors generated a CAR directed to the diasialoganglioside $\mathrm{G}(\mathrm{D} 2 \mathrm{a})$, a tumour-associated antigen expressed by human neuroblastoma cells. They demonstrated that Epstein-Barr virus (EBV)-specific cytotoxic $T$ lymphocytes (CTLs) engineered to express the G(D2a) specific-CAR survive longer than $T$ cells activated by the CD3-specific antibody OKT3 expressing the same CAR, but lacking virus specificity. Moreover, infusion of these genetically modified cells was associated with tumour regression or necrosis in half of the subjects tested [6].

\section{How to build a Chimeric Artificial Receptor}

The ectodomain represents the extracellular part of the artificial T-cell receptor. It is generally composed by a signal peptide, an antigen recognition region and a spacer sequence. The signal peptide directs the nascent protein into the endoplasmic reticulum. This is essential if the receptor needs to be glycosylated and anchored in the cell membrane leading to the CAR expression. The antigen recognition domain is usually a $\mathrm{scFv}$, obtained by the fusion of the variable regions of the heavy $(\mathrm{VH})$ and light (VL) chains of Immunoglobulins (Igs), joined together with a short linker. The latter is usually a serine-glycine rich motif, whose flexibility assures a high mobility capacity to the molecule Figure 1. This chimeric domain retains the specificity of the original Ig, 
despite removal of the constant regions and the introduction of a linker peptide. The traditional method to obtain the scFv was based on the use of mouse hybridoma producing the specific antibody necessary to have the variable fragments of the $\mathrm{VL}$ and $\mathrm{VH}$ chains [7]. A new approach, more suitable in this contest, is represented by the technology of synthetic DNA. To generate the scFv binding domain by a "synthetic DNA " approach, guidelines published by Rydzanicz et al. can be adopted [8]. As a DNA template for the VH and VL fragment it is possible to use a humanized antibody published sequence. Once the final scFv sequence containing the leader sequence and the flexible linker is found and projected, it is possible to proceed with the synthetic DNA generation. The Rydzanicz et al. method is based on dividing the putative sequence into different overlapping oligonucleotides. To generate specific and functional overlapping oligonucleotides, they created a free online software "Assembly PCR oligo maker" http:// www.ncbi.nlm.nih.gov/pmc/articles/PMC1160141/. This software calculates the overlapping oligonucleotides following the putative sequence with specific values of $\mathrm{T}$ melting (Tm), thus avoiding non-specific and random annealing possibilities. The overlapping oligonucleotides are then joined together exploiting a basic PCR reaction in order to generate the putative template. A second reaction of PCR is then needed to amplify the new synthetic template using flanking primers Figure 2.

\section{Clinical application in haematology}

Haematological malignancies represent optimal targets for the exploitation of CARs, because of the bright expression of specific antigens on the surface of tumour cells. Previous studies from our group demonstrated that B-lineage acute lymphoblastic leukaemia can be efficiently targeted by a CAR directed against the CD19 antigen $[9,10]$. We have shown that, after transduction with anti-CD19 CARs, cytokine induced killer (CIK) cells, a peculiar population of effector cells, acquire potent anti-leukemic activity in terms of cytotoxicity, proliferation and release of immunostimulatory cytokines upon specific antigen recognition. In line with these observations, an European consortium http://www. childhope.eu/contents.php have been developed, funded in the contest of a STREP ( $6^{\text {th }}$ framework) to target high-risk B-ALL in molecular relapse after

\section{CLONING ANTI-CD23.CAR scFv WITH SYNTHETIC DNA TECHNOLOGY}

- Synthetic DNA technology: generation of a synthetic anti-CD23 scFv

- Template: the published sequences of a humanized CD23 antibody

$5^{\prime}$

Ideal sequence of DNA
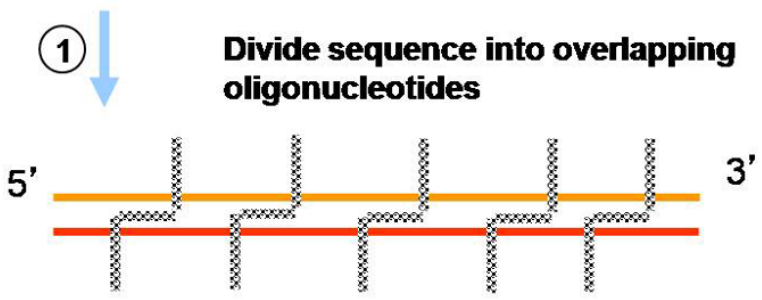
The oligonucleotides cover the whole
sequence

$5^{\prime}$

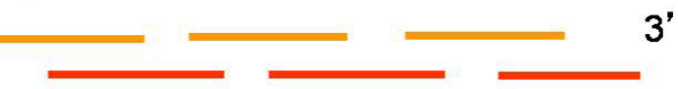

$3^{\prime}$
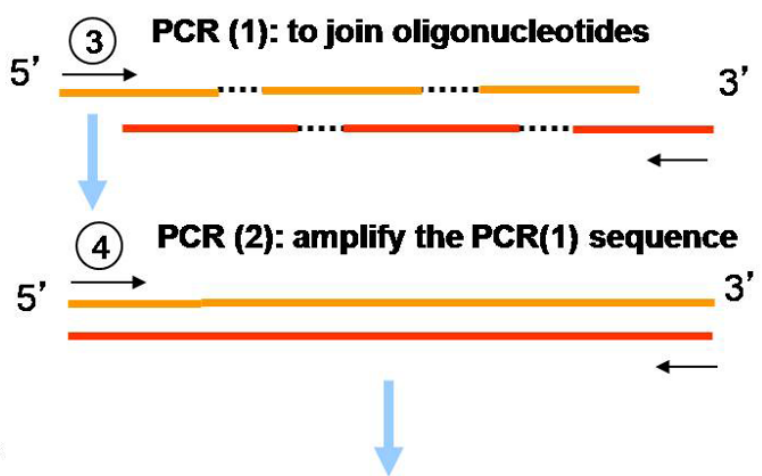

Synthetic anti-CD23 CAR

(5) Cloning the anti-CD23 specific scFv into viral backbone

6) Test functional activity

Figure 2 the Synthetic DNA Technology applied to the anti-CD23.CAR. 
transplantation using donor-derived anti-CD19. CARexpressing EBV-CTLs. The preclinical in vivo data, targeting primary patient-derived high-risk B-ALL [11], demonstrated the efficacy of such an approach and paved the way, for the first time in the field of paediatric leukaemia, for the design of a phase I clinical trial. In this trial paediatric patients, who received allogeneic transplantation, will be infused with donor-derived antiCD19. CAR-expressing EBV-CTLs, as soon as the reappearance of the disease is detected by early Minimal Residual Disease (MRD) analysis. A single injection will be performed after a lympho-depletion schedule by fludarabine and discontinuation of imunosuppression.

Similarly, four other main groups are developing CARbased strategies for targeting B-origin leukaemia-lymphoma neoplasm, by using CD19 as the selected target. Indeed, the MK Brenner's group has recently published interesting even though preliminary observations concerning the in vivo superior effect of second generation CARs containing, beyond the zeta-chain, a costimulatory molecule, specifically the CD28 domain. Patients with B cell lymphomas were infused with two different autologous T-cell products expressing CARs with the same specificity for the CD19 antigen: one CAR encoded both the costimulatory CD28 and the zeta endodomains, while the other presented the zeta endodomain alone. CAR-expressing $\mathrm{T}$ cells containing the CD28 endodomain showed markedly enhanced growth and persistence compared with CAR-expressing $T$ cells encoding the zeta endodomain alone [12]. Similar and promising results have been obtained in humans by the $\mathrm{CH}$ June's and SA Rosenberg's groups, targeting the CD19 antigen in lymphoma patients by using gene-modified autologous $T$ cells $[13,14]$. Both groups observed and measured long-lasting eradication even in case of disseminated tumours, either by single or multiple injections of anti-CD19. CAR-expressing T cells. Lastly, the LJ Cooper's group has recently proposed a clinical-grade non-viral method to transduce $\mathrm{T}$ cells with the antiCD19. CAR: the "Sleeping Beauty" transposon/transposase system. This innovative method is based on the nucleofection/electroporation of plasmidic DNA, allowing cells to be stably transduced in their nucleus and avoiding the use of viral vectors [15].

Other potential optimal targets of CAR-gene transfer are represented by Acute Myeloid Leukaemia (AML) and Chronic Lymphocytic Leukaemia (B-CLL), because of the selective expression of tumour-associated surface antigens, possible targets of CAR recognition.

Immunotoxin-based therapy against $\mathrm{CD} 3^{+}$myeloid leukaemia using gemtuzumab ozogamicin (Mylotarg) [16] had some success, albeit associated with liver (Veno-Occlusive Disease) and haematological toxicity in a significant number of patients [16]. With the exception of acute promyelocytic leukaemia, the curative potential of Mylotarg as a single agent is still limited [16]. Immunotherapy with $T$ cells using unmanipulated donor lymphocyte infusion (DLI) for the treatment of leukaemia recurrence in Haematological Stem Cells Transplantation (HSCT) recipients has shown some positive results in AML, but the use of DLI carries a significant risk of inducing Graft versus Host Disease (GvHD) [17]. The identification of leukaemia-associated antigens eliciting T-cell responses in vitro, has been successful for AML [18]. However, the generation of leukaemia-specific cytotoxic $\mathrm{T}$ cells against AML-associated antigens has been hampered by several factors: the poor immunogenicity of blasts lacking costimulatory molecules and the low frequency of $\mathrm{T}$-cell precursors in antigen-naïve marrow donors or in patients anergized by their own leukaemia. An attractive strategy to overcome these limitations may be represented by the use of human $\mathrm{T}$ cells that bear CARs specific for CD33 molecule. In line with these considerations, we have recently published an in vitro model that strongly demonstrates the efficiency of anti-CD33. CARs towards myeloid cell lines and primary blasts, by using gene modified CIK cells [19]. The infusion of CIK cells in patients with AML relapsing after HSCT is well tolerated, but limited clinical responses were observed [20]. To improve their effector functions against AML, CIK cells were genetically modified with CARs specific for the CD33 myeloid antigen by using SFG-retroviral vectors encoding for anti-CD33-zeta and anti-CD33-CD28-OX40-zeta chimeric receptors. Anti-CD33. CARs modified CIK cells acquired potent cytotoxicity (up to $80 \%$ lysis) against various AML targets, also confirmed in long-term killing experiments. Moreover, a relevant CD33-specific proliferation was measured, accompanied by the release of high levels of immunostimulatory cytokines. The presence of CD28-OX40 in CAR endodomain was associated with a significant amelioration of the antileukaemia activity of modified CIK cells. Representative data showing anti-CD33 and anti CD19 CAR-mediated killing and immunostimolatory capacities are shown in Figure 3. Importantly, even though a certain toxicity against normal haematopoietic $\mathrm{CD} 34^{+}$progenitor cells was measured, their residual haematopoietic activity was anyway preserved [19], thus opening the way for possible clinical applications of the anti-CD33. CAR strategy. In vivo experiments are currently ongoing in order to measure the safety and efficacy profile of anti-CD33. CAR-expressing cells in an immunodeficient mouse model.

Similarly to ALL and AML, B-CLL may represent as well an interesting target for CAR strategy. B-CLL cells expressing CD19 and CD20dim are suitable to be targeted with $T$ cells redirected against these pan- $B$ 

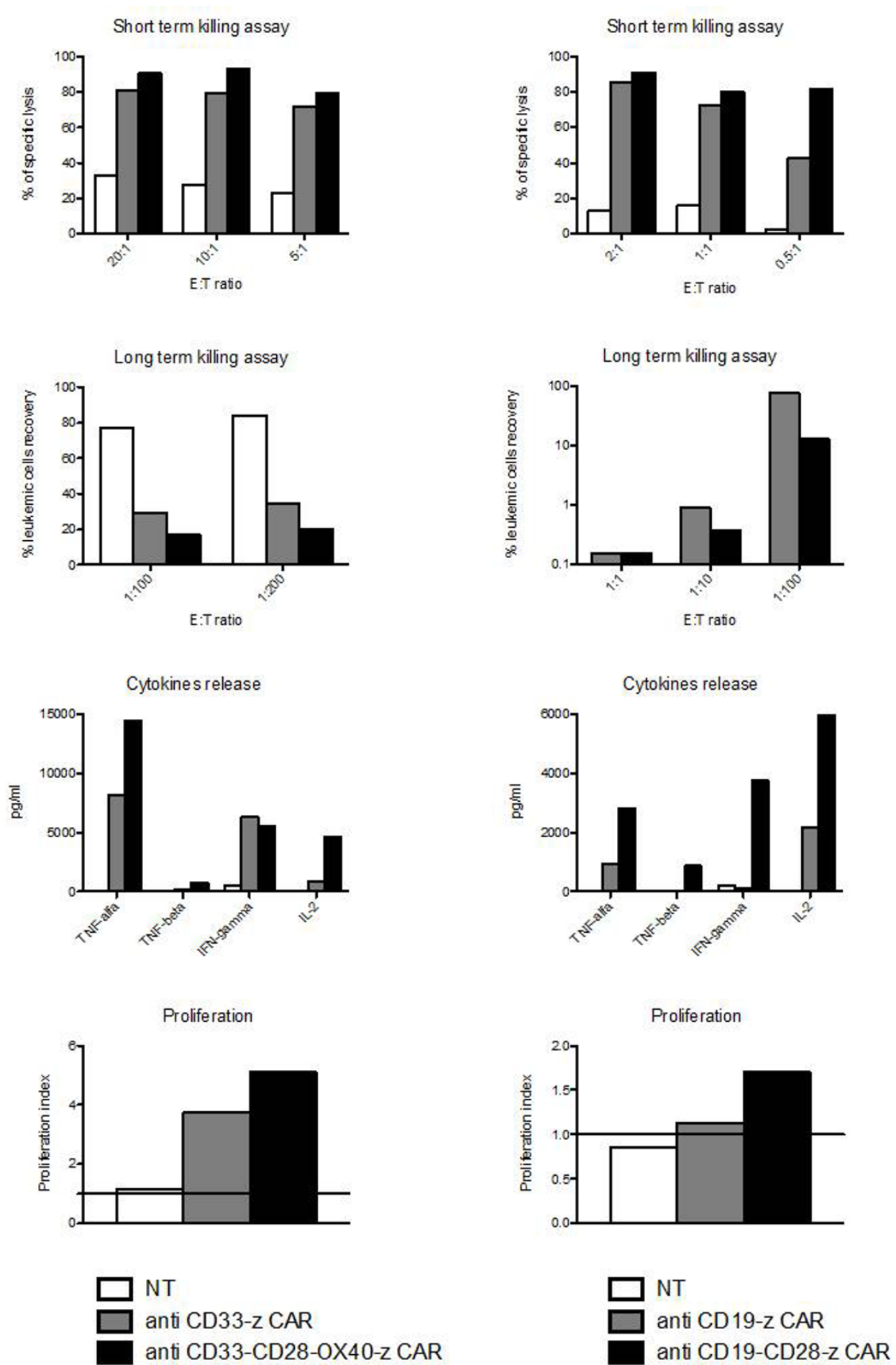

Figure 3 CARs activity towards myeloid $\left(\mathrm{CD} 33^{+}\right)$and lymphoid $\left(\mathrm{CD} 19^{+}\right)$acute leukaemias. The figures show different tests adopted to measure the efficacy of transduced T cells. The panels on the left side describe the effect on AML cells, whilst the right panels on ALL cells. The test shown are, starting from the top: 1) short term cytotoxicity, by classic Chromium release assay; 2) long-term cytotoxicity, measured as recovery of leukaemia cells after 1-week of co-incubation with effectors cells; 3) cytokine release, by Elisa tests; 4) proliferation index, measured as ration versus the basal number by thymidine incorporation assay. All the tests are described in details in reference no. 19. 
markers. In fact, CARs have been generated to target these self tissue-restricted B-cell antigens [12-15]. However, B-CLL hypo-gammaglobulinemia is present in approximately $8 \%$ of patients at diagnosis and progressively increases along the natural history of the disease. Thus, targeting pan-B markers can potentially further compromised the immunity of these patients. A more selective self-antigen in B-CLL that can be more suitable is the CD23 molecule, because of its higher expression on B-CLL cells as compared to normal B lymphocytes [21]. CD23 is the low-affinity receptor for IgE and its expression and function is physiologically restricted to IgE-secreting B lymphocytes, mast cells, platelets and dendritic cells. Lumiliximab (L-mab), a macaque-human chimeric anti-CD23 monoclonal antibody, has been used in a Phase I-II study, to test its safety, efficacy, and pharmacokinetics. In the last study 31 patients received either $375 \mathrm{mg} / \mathrm{m}(2)(\mathrm{n}=3)$ or $500 \mathrm{mg} / \mathrm{m}(2)(\mathrm{n}=28)$ of L-mab in combination with Fludarabine, Cyclophosphamide and Rituximab (FCR) for 6 cycles [22]. The overall response rate was $65 \%$, with $52 \%$ of patients achieving a complete response (CR). Study-related adverse events were mild and evidence of clinical activity consisted of reductions in absolute lymphocyte counts and lymphonodes size. T cells redirected against CD23 through a specific CAR may further improve these results. In line with these observations, we have recently published an in vitro and in vivo model that corroborates this hypothesis [23]. We cloned and expressed in T lymphocytes a novel CAR targeting the CD23 antigen. Anti-CD23. CAR-expressing $\mathrm{T}$ cells showed specific cytotoxic activity against $\mathrm{CD} 23^{+}$tumour cell lines (average lysis $42 \%$ ) and primary CD23 ${ }^{+}$CLL cells (average lysis $58 \%$ ). This effect was obtained without a significant toxicity against normal B lymphocytes, in contrast to CARs targeting CD19 or CD20 antigens, which are also physiologically expressed by normal B lymphocytes. Moreover, autologous CLL-derived-CD23. CAR-expressing T cells significantly released inflammatory cytokines and IL-2 was also produced to sustain the CD23-driven proliferation of such modified $\mathrm{T}$ cells. Redirected $\mathrm{T}$ cells were also effective in vivo in a CLL Rag2(-/-) $\gamma \mathrm{c}(-/-)$ xenograft mouse model [24]. Indeed, the infusion of anti-CD23. CAR-expressing $\mathrm{T}$ cells resulted in a significant delay in the growth of the CLL-derived cell line (MEC-1). These data suggest that anti-CD23. CAR-expressing $T$ cells represent a selective immunotherapy approach for the elimination of $\mathrm{CD} 23^{+}$leukaemia cells in patients affected by B-CLL.

Despite the promising results obtained so far, CAR strategy might be further optimized. Several reports indicate that the addition of costimulatory molecules (such as CD28, ICOS, CD134 or CD137), either as single domain or as multiple combinations, to the signalling CAR endodomain induces a higher rate of proliferation, higher levels of IL-2 secretion and prolonged effector cells survival with a subsequent better activity in vivo [25]. An additional approach to ameliorate CAR-mediated effector functions might be the inactivation of inhibitory molecules. These inhibitory ligands are expressed on various tumour cells and are associated with functional impairment of extensively in vitro stimulated T cells: their blockade can accelerate tumour eradication [26]. A different strategy to guarantee an improved and totally physiological activation of $\mathrm{T}$ cells can be achieved exploiting an activated native TCR, such as a viral targeting TCR, in addition to the CAR specificity (the so-called "dual-specific" $T$ cells) [6]. In this condition, the activation of the natural TCR should provide a powerful stimulus, maintaining at the same time the killing capacity, the proliferative activity and the durable persistence of the CAR-related functions. Indeed, MK Brenner's group has recently adopted EBVspecific CTLs, transducing them with a CAR targeting the $G(D 2 a)$ antigen expressed by neuroblastoma cells. Such manipulated cells preserved an intact activity towards the viral target and also killed the neuroblastoma cells through the anti-G(D2a). CAR. As described above, this strategy has been proved to be feasible and efficient in a recent phase I clinical trial [6].

Alternatively to the use of EBV-CTLs, other T-cell subsets have shown some potential for future adoptive immunotherapeutic approaches. In line with previous considerations, there is enough evidence to support the in vivo use of chimeric EBV-CTLs in paediatric relapsed/refractory ALL patients, as planned in a Phase I trial in the context of the "Childhope" STREP-funded network. However, additional preclinical experiments are crucial to compare the respective anti-tumour efficacy of chimeric EBV-CTLs, chimeric CIK cells and chimeric gamma9delta2 $\mathrm{T}$ cells (GDT) for future clinical applications. CIK cells are T cells with natural killer cell phenotype and function, enriched in CD3+CD56+ cells [19], that can be easily expanded from human peripheral blood mononuclear cells up to 200-1000 fold in 14-21 days of culture after an initial priming with IFN-gamma and OKT-3 followed by repeated stimulation with highdoses of IL-2 [20]. It has been demonstrated that CIK cells can lyse a broad array of tumour targets in a nonMHC-restricted manner and display an in vivo potent anti-tumour activity, while having reduced propensity to induce GvHD [27]. Phase I studies have been performed with CIK cells in various contexts, where no toxicity was observed and several partial responses were detected [20-27]. Similarly, human peripheral GDT T cells are a proved alternative to conventional CTLs. The vast majority of peripheral blood GDT cells, that represent 0.5 to $5.0 \%$ of whole peripheral blood $\mathrm{T}$ cells in 
humans, express TCR composed of a restricted set of variable regions called Vgamma9 and Vdelta2. Beside their known anti-infectious activity -in particular following allogeneic HSCT - it was shown that GDT cells are able to kill a wide variety of tumour cell lines from very diverse origins [28]. GDT cells can be selectively expanded in vivo or in vitro in the presence of aminobisphosphonates without prior antigen priming [29]. Recently, it has been shown that human GDT cells can be expanded in the presence of zoledronate and efficiently transduced with a retroviral vector encoding a CD19-specific CAR. Transduced GDT cells powerfully recognised and lysed antigen-expressing tumour cell targets [30]. To unravel such an important issue, we have recently published a comparison, in an in vitro model, of the above mentioned populations as putative effectors of CAR-mediated immunotherapy [31]. Our results indicate that the expression of an anti-CD33-zeta chimeric receptor potently and similarly increases the antileukaemic functions of different effector T-cell subtypes. This underlines the impossibility to identify a more potent $\mathrm{T}$ cell population through an in vitro analysis. Moreover, these results are consistent with recent observations that have emerged from clinical trials with CAR-modified $\mathrm{T}$ cells, suggesting the need to perform such type of studies in the human setting.

An important consideration for the clinical applicability of CAR strategy is represented by the safety issues concerning the use of integrating vector for gene transfer, as well as the potential reactivity of CAR-transduced cells against host-normal cells expressing the target antigen. Furthermore, the potential hazards associated with the use of CAR containing costimulatory or growth-promoting molecules that may improve the survival and the proliferation of manipulated $T$ cells need to be investigated [1-4]. These limitations can be overcome by introducing suicide genes that constitute a back-up control to be used in case of unexpected reactivity of transduced cells [32]. Several suicide gene strategies have been described so far. The most described approach has been based on the thymidine kinase gene of the Herpes Simplex virus (HSV-TK). Expression of the HSV-TK gene by transduced $\mathrm{T}$ cells renders them susceptible to the effects of gancyclovir (GCV). Several groups have reported that transduced $\mathrm{T}$ cells retained their anti-leukaemia effect, including long-lasting remissions in some patients [33]. However, HSV-TK is highly immunogenic in humans. The most recently described strategy is the inducible Casp9 suicide system, which is based on a fusion protein constituted by human caspase 9 and the modified human FK506 binding protein (FKBP), that allows conditional dimerisation triggered by a chemical inducer of dimerisation
(CID) [34]. Other suicide genes that have been studied include the human CD20, which is targeted by the monoclonal antibody Rituximab [35], and a mutant human thymidylate kinase (mTMPK), which renders transduced cells susceptible to zidovudine (AZT) [36]. A fundamental step to identify the optimal suicide approach for clinical intervention requires a direct comparison of all these systems. Our preliminary results (unpublished data) confirm a substantial equivalence of the HSV-TK and Casp9-CID systems, having the latter the double advantage of not being immunogenic and exerting its activity in a more rapid timeframe.

\section{Conclusions}

In conclusion, CARs represent a potential useful tool to fight various resistant forms of leukaemia. As recently discussed by Helen Heslop [37], more than 10 clinical trials using second or third-generation CARs are currently present on http://ClinicalTrials.gov, and there is some encouraging preliminary evidence of their clinical efficacy. On the other side, two serious adverse events have been reported. The first event [38] occurred in a patient with largely metastatic colon cancer who was infused with more than $10^{10} \mathrm{~T}$ cells expressing a thirdgeneration CAR targeting HER2, after being pre-treated with an intensive lymphodepletion regimen. The patient rapidly presented pulmonary toxicity within few minutes, followed by cardiac arrest and finally died few days later. The investigators concluded that the toxicity was due to targeting of low levels of HER2 on pulmonary endothelium by transgenic $\mathrm{T}$ cells. In the second clinical case, Brentjens and colleagues described a patient with bulky CLL and extensive previous chemotherapy treatment who received autologous $\mathrm{T}$ cells expressing a second generation anti-CD19. CAR at a dose of $3 \times 10^{7}$ cells $/ \mathrm{kg}$ after being lymphodepleted with cyclophosphamide [39]. This patient suddenly developed fever, hypotension, and dyspnea few hours after infusion, with rapid fatal progression. An autopsy did not reveal a clear cause of death. It was concluded that low grade sepsis was the most likely triggering factor in this heavily pre-treated patient, but it was also hypothesized that a cyclophosphamide-induced "cytokine storm" may have potently augmented the in vivo activation process of modified $T$ cells.

All these aspects have been currently widely considered and discussed by many researchers and regulatory experts in the field of cell and gene therapy. Different schedules of administration (dose-escalation) with a reduced cell numbers or fractionated doses, together with a better choice of pre-administration lympho-depletive regimens, in patients with minimal residual disease, would probably diminish 
the possibility of observing severe adverse events. Withal, the use of CARs containing suicide-gene switch-off mechanisms could be helpful in case of offtarget side events $[4,40]$.

\author{
Acknowledgements \\ We thank the relevant contribution of AIRC Molecular clinical oncology 5 \\ per mille, "Innate immunity in cancer. Molecular targeting and cellular \\ therapy", 9962. Ettore Biagi was supported by Associazione Italiana per la \\ Ricerca sul cancro (AIRC) Milano (AIRC 2007 (4069), AIRC 2007 (4636)), \\ "Redirecting T lymphocytes to leukaemia antigens by Chimeric T-cell \\ Receptors: targeted therapy of leukaemias"and "Progetto Integrato \\ Oncologia 2006", Ministero della Salute -Direzione Generale della Ricerca \\ Scientifica e Tecnologica. Andrea Biondi was supported by AIRC: "Childhood \\ ALL: from clinical studies to research questions to understand molecular \\ history and pathogenesis". Virna Marin and Irene Pizzitola were supported by \\ the grant from STREP2006 (6th framework; LSHC-ct-2006-037381) "Chimeric T \\ cells for the treatment of pediatric cancers (Childhope)". \\ We would like to thank also the Fondazione "Matilde Tettamanti", the \\ Comitato "Stefano Verri" and Comitato "Maria Letizia Verga" for their \\ continuous and generous support.
}

\section{Authors' contributions}

$E B$ and $A B$ conceived and wrote the article. VM and GMPGA performed and wrote the literature search. VM and EC edited the parts (and performed literature search) concerning applications of CARs in B-cell malignancies. VM, IP and ST edited the parts (and performed literature search) concerning applications of CARs in AML. GMPGA edited the parts (and performed literature search) concerning applications of CARs in CLL. GMPGA, IP, ST, EC contributed to figures preparation. VM edited the article for publication. All authors have read and approved the script.

\section{Competing interests}

The authors declare that they have no competing interests.

Received: 23 August 2011 Accepted: 22 September 2011

Published: 22 September 2011

\section{References}

1. Rossig C, Brenner MK: Genetic modification of T lymphocytes for adoptive immunotherapy. Mol Ther 2004, 10:5-18, Review.

2. Dotti G, Heslop HE: Current status of genetic modification of T cells for cancer treatment. Cytotherapy 2005, 7:262-272, Review.

3. Biagi E, Marin V, Giordano Attianese GM, Dander E, D'Amico G, Biondi A: Chimeric T-cell receptors: new challenges for targeted immunotherapy in hematologic malignancies. Haematologica 2007, 92:381-388, Review.

4. Kohn DB, Dotti G, Brentjens R, Savoldo B, Jensen M, Cooper $L$, June $C H$, Rosenberg S, Sadelain M, Heslop HE: CARs on track in the clinic. Mol Ther 2011, 19:432-438.

5. Rössig C, Brenner MK: Chimeric T-cell receptors for the targeting of cancer cells. Acta Haematol 2003, 110:154-159, Review.

6. Pule MA, Savoldo B, Myers GD, Rossig C, Russell HV, Dotti G, Huls MH, Liu E, Gee AP, Mei Z, Yvon E, Weiss HL, Liu H, Rooney CM, Heslop HE, Brenner MK: Virus-specific T cells engineered to coexpress tumor-specific receptors: persistence and antitumor activity in individuals with neuroblastoma. Nat Med 2008, 14:1264-1270.

7. Kershaw MH, Teng MW, Smyth MJ, Darcy PK: Supernatural T cells: genetic modification of T cells for cancer therapy. Nat Rev Immunol 2005, 5:928-940

8. Rydzanicz Roman, Sharon Zhao X, Philip E: Johnson Assembly PCR oligo maker: a tool for designing oligodeoxynuleotides for constructing long DNA molecules for RNA production. Nucleic Acids Research 2005, 33 Web Server: W521-525.

9. Marin V, Dander E, Biagi E, Introna M, Fazio G, Biondi A, D'Amico G: Characterization of in vitro migratory properties of anti-CD19 chimeric receptor-redirected CIK cells for their potential use in B-ALL immunotherapy. Exp Hematol 2006, 34:1219-1229.
10. Marin V, Kakuda H, Dander E, Imai C, Campana D, Biondi A, D'Amico G: Enhancement of the anti-leukemic activity of cytokine induced killer cells with an anti-CD19 chimeric receptor delivering a 4-1BB-zeta activating signal. Exp Hematol 2007, 35:1388-1397.

11. Landmeier S, Altvater B, Pscherer S, Meltzer J, Sebire N, Pule M, Vera J, Hotfilder M, Juergens H, Vormoor J, Rossig C: Cytotoxic T cells transduced with chimeric anti-CD19 receptors prevent engraftment of primary lymphoblastic leukemia in vivo. Leukemia 2010, 24:1080-1084.

12. Savoldo B, Ramos CA, Liu E, Mims MP, Keating MJ, Carrum G, Kamble RT, Bollard CM, Gee AP, Mei Z, Liu H, Grilley B, Rooney CM, Heslop HE, Brenner MK, Dotti G: CD28 costimulation improves expansion and persistence of chimeric antigen receptor-modified T cells in lymphoma patients. J Clin Invest 2011, 121:1822-1826.

13. Zhao $Y$, Moon E, Carpenito C, Paulos CM, Liu X, Brennan AL, Chew A, Carroll RG, Scholler J, Levine BL, Albelda SM, June CH: Multiple injections of electroporated autologous $T$ cells expressing a chimeric antigen receptor mediate regression of human disseminated tumor. Cancer Res 2010, 70:9053-9061.

14. Kochenderfer JN, Wilson WH, Janik JE, Dudley ME, Stetler-Stevenson M, Feldman SA, Maric I, Raffeld M, Nathan DA, Lanier BJ, Morgan RA, Rosenberg SA: Eradication of B-lineage cells and regression of lymphoma in a patient treated with autologous $T$ cells genetically engineered to recognize CD19. Blood 2010, 116:4099-4102.

15. Jin Z, Maiti S, Huls H, Singh H, Olivares S, Mátés L, Izsvák Z, Ivics Z, Lee DA, Champlin RE, Cooper $\amalg$ : The hyperactive Sleeping Beauty transposase SB100X improves the genetic modification of T cells to express a chimeric antigen receptor. Gene Ther 2011.

16. Tsimberidou AM, Giles FJ, Estey E, O'Brien S, Keating MJ, Kantarjian HM: The role of gemtuzumab ozogamicin in acute leukaemia therapy. $\mathrm{Br} J$ Haematol 2006, 132:398-409, Review.

17. Takami A, Okumura H, Yamazaki H, Kami M, Kim SW, Asakura H, Endo T, Nishio M, Minauchi K, Kumano K, Sugimori N, Mori S, Takemoto $Y$ Shimadoi S, Ozaki J, Takaue Y, Nakao S: Prospective trial of high-dose chemotherapy followed by infusions of peripheral blood stem cells and dose-escalated donor lymphocytes for relapsed leukemia after allogeneic stem cell transplantation. Int J Hematol 2005, 82:449-455.

18. Knights AJ, Weinzierl AO, Flad T, Guinn BA, Mueller L, Mufti GJ, Stevanovic S, Pawelec G: A novel MHC-associated proteinase 3 peptide isolated from primary chronic myeloid leukaemia cells further supports the significance of this antigen for the immunotherapy of myeloid leukaemias. Leukemia 2006, 20:1067-1072.

19. Marin V, Pizzitola I, Agostoni V, Attianese GM, Finney H, Lawson A, Pule M, Rousseau R, Biondi A, Biagi E: Cytokine-induced killer cells for cell therapy of acute myeloid leukemia: improvement of their immune activity by expression of CD33-specific chimeric receptors. Haematologica 2010, 95:2144-2152.

20. Introna M, Borleri G, Conti E, Franceschetti M, Barbui AM, Broady R, Dander E, Gaipa G, D’Amico G, Biagi E, Parma M, Pogliani EM, Spinelli O, Baronciani D, Grassi A, Golay J, Barbui T, Biondi A, Rambaldi A: Repeated infusions of donor-derived cytokine-induced killer cells in patients relapsing after allogeneic stem cell transplantation: a phase I study. Haematologica 2007, 92:952-959.

21. Damle RN, Ghiotto F, Valetto A, Albesiano E, Fais F, Yan XJ, Sison CP, Allen SL, Kolitz J, Schulman P, Vinciguerra VP, Budde P, Frey J, Rai KR, Ferrarini M, Chiorazzi N: B-cell chronic lymphocytic leukemia cells express a surface membrane phenotype of activated, antigen-experienced $B$ lymphocytes. Blood 2002, 99:4087-4093.

22. Byrd JC, Kipps TJ, Flinn IW, Castro J, Lin TS, Wierda W, Heerema N, Woodworth J, Hughes S, Tangri S, Harris S, Wynne D, Molina A, Leigh B, O'Brien S: Phase 1/2 study of lumiliximab combined with fludarabine, cyclophosphamide, and rituximab in patients with relapsed or refractory chronic lymphocytic leukemia. Blood 2010, 115:489-495.

23. Giordano Attianese GMP, Marin V, Hoyos V, Savoldo B, Pizzitola I, Tettamanti S, Agostoni V, Parma M, Ponzoni M, Bertilaccio MT, Ghia P, Biondi A, Dotti G, Biagi E: In vitro and in vivo model of a novel immunotherapy approach for chronic lymphocytic leukemia by antiCD23 chimeric antigen receptor. Blood 2011, 117:4736-4745.

24. Bertilaccio MT, Scielzo C, Simonetti G, Ponzoni M, Apollonio B, Fazi C, Scarfò L, Rocchi M, Muzio M, Caligaris-Cappio F, Ghia P: A novel Rag2-/-gammac-/-xenograft model of human CLL. Blood 2010, 115:1605-1609. 
25. Pulè MA, Straathof KC, Dotti G, Heslop HE, Rooney CM, Brenner MK: A chimeric $T$ cell antigen receptor that augments cytokine release and supports clonal expansion of primary human T cells. Mol Ther 2005, 12:933-941.

26. Okazaki T, Honjo T: PD-1 and PD-1 ligands: from discovery to clinical application. Int Immunol 2007, 19:813-824, Review.

27. Linn YC, Hui KM: Cytokine-induced NK-like T cells: from bench to bedside. J Biomed Biotechnol 2010, 2010:435745, Epub 2010 Mar 30 Review.

28. Ferrarini M, Ferrero E, Dagna L, Poggi A, Zocchi MR: Human gammadelta T cells: a nonredundant system in the immune-surveillance against cancer. Trends Immunol 2002, 23:14-18, Review.

29. Viey E, Fromont G, Escudier B, Morel Y, Da Rocha S, Chouaib S, Caignard A: Phosphostim-activated gamma delta T cells kill autologous metastatic renal cell carcinoma. J Immunol 2005, 174:1338-1347.

30. Rischer M, Pscherer S, Duwe S, Vormoor J, Jürgens H, Rossig C: Human gammadelta $\mathrm{T}$ cells as mediators of chimaeric-receptor redirected antitumour immunity. Br J Haematol 2004, 126:583-592.

31. Pizzitola I, Agostoni V, Cribioli E, Pule M, Rousseau R, Finney H, Lawson A, Biondi A, Biagi E, Marin V: In Vitro Comparison of Three Different Chimeric Receptor-modified Effector T-cell Populations for Leukemia Cell Therapy. J Immunother 2011, 34:469-479.

32. Ramos CA, Dotti G: Chimeric antigen receptor (CAR)-engineered lymphocytes for cancer therapy. Expert Opin Biol Ther 2011, 11:855-873.

33. Borchers S, Provasi E, Silvani A, Radrizzani M, Benati C, Dammann E, Krons A, Kontsendorn J, Schmidtke J, Kuehnau W, von Neuhoff N, Stadler M, Ciceri F, Bonini C, Ganser A, Hertenstein B, Weissinger EM: Genetically Modified Donor Leukocyte Transfusion and Graft-Versus-Leukemia Effect After Allogeneic Stem Cell Transplantation. Hum Gene Ther 2011.

34. Hoyos V, Savoldo B, Quintarelli C, Mahendravada A, Zhang M, Vera J, Heslop HE, Rooney CM, Brenner MK, Dotti G: Engineering CD19-specific T lymphocytes with interleukin-15 and a suicide gene to enhance their anti-lymphoma/leukemia effects and safety. Leukemia 2010, 24:1160-1170.

35. Vogler I, Newrzela S, Hartmann S, Schneider N, von Laer D, Koehl U, Grez M: An improved bicistronic CD20/tCD34 vector for efficient purification and in vivo depletion of gene-modified T cells for adoptive immunotherapy. Mol Ther 2010, 18:1330-1338.

36. Sato T, Neschadim A, Konrad M, Fowler DH, Lavie A, Medin JA: Engineered human tmpk/AZT as a novel enzyme/prodrug axis for suicide gene therapy. Mol Ther 2007, 15:962-970.

37. Heslop HE: Safer CARS. Mol Ther 2010, 18:661-662.

38. Morgan RA, Yang JC, Kitano M, Dudley ME, Laurencot CM, Rosenberg SA: Case report of a serious adverse event following the administration of T cells transduced with a chimeric antigen receptor recognizing ERBB2. Mol Ther 2010, 18:843-851.

39. Brentjens R, Yeh R, Bernal Y, Riviere I, Sadelain M: Treatment of chronic lymphocytic leukemia with genetically targeted autologous $T$ cells: case report of an unforeseen adverse event in a phase I clinical trial. Mol Ther 2010, 18:666-668.

40. Ertl HC, Zaia J, Rosenberg SA, June CH, Dotti G, Kahn J, Cooper LJ, Corrigan-Curay J, Strome SE: Considerations for the clinical application of chimeric antigen receptor $\mathrm{T}$ cells: observations from a recombinant DNA Advisory Committee Symposium held June 15, 2010. Cancer Res 2011, 71:3175-3181.

doi:10.1186/1824-7288-37-46

Cite this article as: Biagi et al:: New advances in leukaemia

immunotherapy by the use of Chimeric Artificial Antigen Receptors

(CARs): state of the art and perspectives for the near future. Italian

Journal of Pediatrics 2011 37:46.

\section{Submit your next manuscript to BioMed Central and take full advantage of:}

- Convenient online submission

- Thorough peer review

- No space constraints or color figure charges

- Immediate publication on acceptance

- Inclusion in PubMed, CAS, Scopus and Google Scholar

- Research which is freely available for redistribution

Submit your manuscript at www.biomedcentral.com/submit
Biomed Central 